\title{
Glucose-Lowering Medications and Post-Dementia Survival in Patients with Diabetes and Dementia
}

Juraj Secnik $^{\mathrm{a}, \mathrm{b}, *}$, Hong Xu $\mathrm{u}^{\mathrm{a}, \mathrm{c}}$, Emilia Schwertner ${ }^{\mathrm{a}}$, Niklas Hammar ${ }^{\mathrm{d}}$, Michael Alvarsson ${ }^{\mathrm{e}}$, Bengt Winblad $^{\mathrm{f}, \mathrm{g}}$, Maria Eriksdotter ${ }^{\mathrm{a}, \mathrm{g}}$, Sara Garcia-Ptacek ${ }^{\mathrm{a}, \mathrm{g}}$ and Dorota Religa ${ }^{\mathrm{a}, \mathrm{g}}$

a Division of Clinical Geriatrics, Center for Alzheimer Research, Department of Neurobiology, Care Sciences and Society, Karolinska Institutet, Huddinge, Sweden

${ }^{\mathrm{b}}$ Department of Neurology, Charles University, Second Faculty of Medicine, Motol University Hospital, Prague, Czech Republic

${ }^{\mathrm{c}}$ Department of Medical Epidemiology and Biostatistics, Karolinska Institutet, Stockholm, Sweden

${ }^{\mathrm{d}}$ Institute of Environmental Medicine, Karolinska Institutet, Stockholm, Sweden

${ }^{\mathrm{e}}$ Growth and Metabolism, Department of Molecular Medicine and Surgery, Karolinska Institutet, Stockholm, Sweden

${ }^{\mathrm{f}}$ Division of Neurogeriatrics, Center for Alzheimer Research, Department of Neurobiology, Care Sciences and Society, Karolinska Institutet, Stockholm, Sweden

${ }^{\mathrm{g}}$ Theme Aging, Karolinska University Hospital, Huddinge, Sweden

Accepted 10 December 2021

Pre-press 13 January 2022

\begin{abstract}
.
Background: The effectiveness of glucose-lowering drugs (GLDs) is unknown among patients with dementia. Objective: To analyze all-cause mortality among users of six GLDs in dementia and dementia-free subjects, respectively. Methods: This was a longitudinal open-cohort registry-based study using data from the Swedish Dementia Registry, Total Population Register, and four supplemental registers providing data on dementia status, drug usage, confounders, and mortality. The cohort comprised 132,402 subjects with diabetes at baseline, of which 11,401 (8.6\%) had dementia and 121,001 (91.4\%) were dementia-free. Subsequently, comparable dementia - dementia-free pairs were sampled. Then, as-treated and intention-to-treat exposures to metformin, insulin, sulfonylurea, dipeptidyl-peptidase-4 inhibitors, glucagon-like peptide-1 analogues (GLP-1a), and sodium-glucose cotransporter-2 inhibitors (SGLT-2i) were analyzed in the parallel dementia and dementia-free cohorts. Confounding was addressed using inverse-probability weighting and propensity-score matching, and flexible parametric survival models were used to produce hazard ratios (HR) and $95 \%$ confidence intervals (CI) of the association between GLDs and all-cause mortality.

Results: In the as-treated models, increased mortality was observed among insulin users with dementia (HR 1.34 [95\% CI $1.24-1.45])$ as well as in dementia-free subjects (1.54 [1.10-1.55]). Conversely, sulfonylurea was associated with higher mortality only in dementia subjects $(1.19$ [1.01-1.42]). GLP-1a $(0.44[0.25-0.78])$ and SGLT-2i users with dementia $(0.43$ [0.23-0.80]) experienced lower mortality compared to non-users.

Conclusion: Insulin and sulfonylurea carried higher mortality risk among dementia patients, while GLP-1a and SGLT-2i were associated with lower risk. GLD-associated mortality varied between dementia and comparable dementia-free subjects. Further studies are needed to optimize GLD use in dementia patients.
\end{abstract}

Keywords: Antidiabetics, dementia, diabetes, hyperglycemia, mortality, propensity-score

\footnotetext{
${ }^{*}$ Correspondence to: Juraj Secnik, MD, PhD, Division of Clinical Geriatrics, Center for Alzheimer Research, Department of Neurobiology, Care Sciences and Society, Karolinska
}

Institutet, Neo, Blickagången 16, 14152 Huddinge, Sweden. Tel.: +46720088687; E-mail: juraj.secnik@ki.se. 


\section{INTRODUCTION}

Diabetes is a major comorbidity in patients with dementia, where approximately $13-20 \%$ of all dementia patients are co-diagnosed with diabetes $[1,2]$.

The relationship between dementia and diabetes is bilateral-diabetes substantially increases the risk of developing dementia [3] and diabetes selfmanagement depends on patients' cognitive health [4]. Currently, no dementia-modifying medication is available, therefore the quality of diabetes care becomes crucial. Due to different propensities for hypoglycemia among glucose-lowering drugs (GLDs) [5], the concern for additional cognitive decline in patients with dementia is valid [6]. Moreover, cognitive functioning is a major predictor of adequate self-management of diabetes [5, 7], which puts further stress on good pre-dementia and post-dementia diabetes treatment. Frequent cognitive screening, avoidance of hypoglycemia, and treatment deintensification are commonly mentioned in the diabetes guidelines for older patients [4]; however, these measures have not been studied in patients with dementia. Specifically, extensive research was done among the general diabetes population [8-10]; yet, it is unclear how individual GLD groups impact survival in patients with dementia. The presence of progressive neurodegenerative disorder is a major variable in diabetes care, and the optimization of GLD use in these patients is of clinical interest. To determine the dementia-specific associations between individual GLD and long-term all-cause mortality, we have assessed the use of six major glucose-lowering medications, separately among patients with dementia and comparable dementia-free subjects living in Sweden.

\section{MATERIALS AND METHODS}

This prospective open-cohort study was based on data from five Swedish national registers and one database, with the unique mandatory Swedish personal identification number used to merge information. The National Board of Health and Welfare and Statistics Sweden oversaw the data de-identification and merge. We provide a short summary of the study population as well as detailed description of the data below.

Briefly, the study population is based on a larger data extraction comprising 1,752,659 subjects:
424,624 (24.2\%) patients diagnosed with dementia and up to four matched dementia-free controls $(1,328,035$ [75.8\%]). Then, we selected the subpopulation of subjects with diabetes with and without dementia, where dementia diagnosis had to be recorded in the Swedish Dementia Registry (SveDem) (184,560 subjects, 13,508 subjects with dementia from SveDem). After applying further exclusion criteria, 132,402 subjects with diabetes mellitus $(11,401$ [8.6\%] with dementia) were the basis for propensity-score (PS) matching on dementia status to assure comparability. Afterwards, survival analyses were performed in the parallel dementia and dementia-free cohorts (Supplementary Figure 1).

\section{Swedish dementia registry}

SveDem is the largest quality-of-care registry for dementia in the world and has been described previously $[11,12]$. SveDem was established in 2007 with the purpose to register all dementia patients in Sweden at the time of diagnosis and standardize their care. Patient variables include clinical characteristics (e.g., Mini-Mental State Examination [MMSE]), sociodemography (e.g., living arrangements), community support (e.g., daycare), and chronic pharmacological treatment [11]. Dementia diagnosis is determined primarily using ICD-10 and comprise Alzheimer's disease, mixed-pathology dementia, vascular dementia, unspecified, and other dementia types. In addition, the McKeith criteria are used for the diagnosis of dementia with Lewy bodies, Lund-Manchester criteria for frontotemporal dementia and criteria by the Movement Disorder Society for the diagnosis of Parkinson's disease dementia [11]. Dementia with Lewy bodies and Parkinson's disease dementia were merged into one group, Lewy body dementia [13].

\section{Dementia cases}

To improve precision of dementia cases, only diagnoses of dementia from SveDem were included, while patients with dementia diagnoses included in other registers (Supplementary List 1) and not recorded by SveDem were excluded. Specifically, only patients with diagnosed dementia and registration to SveDem between May 1, 2007 until October 16,2018 who were also diagnosed with diabetes were included (11,401 patients, Supplementary Figure 1, sections on diabetes mellitus below). 


\section{Swedish total population register (Population} Register)

Population Register contains information on main life events of the Swedish population (e.g., birth, marital status, death) and is available in computerized form since 1968. Population Register is used for official population statistics and is maintained by Statistics Sweden [14].

\section{Dementia-free controls and study sample description}

In the original data extraction, a pool of dementiafree subjects was extracted from the Population Register and matched with dementia subjects on birth year ( \pm 3 years), sex, and the place of residence (county). After selection criteria were applied, the final study sample comprised 132,402 subjects with diabetes (11,401 with dementia, 121,001 dementia-free). From this cohort, eligible subjects were sampled (subjects without history of using certain GLD) and then further matching on dementia status was done to provide comparability among eligible subjects with and without dementia. The whole selection and matching process is described in Supplementary Figure 1 and Supplementary List 1, and the description of the whole cohort $(132,402$ subjects) is summarized in Supplementary Table 1. As a convention, the term "index date" will refer to the date of dementia diagnosis in the dementia cohort and assigned index date in the dementia-free cohort.

\section{Swedish national patient register}

The Patient Register provided records on inpatient diagnoses since 1998 (specialized outpatient visits since 2001 [15]) until December 31, 2017. The diagnoses were coded according to the $10^{\text {th }}$ version of the International Classification of Diseases (ICD-10) [16].

\section{Diabetes mellitus}

Diabetes was identified by the ICD-10 codes E10-E14 in the Patient Register or by antidiabetic treatment (ATC code A10) included in the Drug Register prior to and including the index date. Subsequently, diabetes was grouped into three types: type 1 diabetes, type 2 diabetes, and other/unspecified diabetes (for details on extraction and coding, see Supplementary Algorithm 1). Only patients with type 2 diabetes and other/unspecified types were included in the cohort (see Supplementary Algorithm 1).
Baseline diabetes duration was based on the difference between the index date and the date of the earliest record of diabetes, either in the Patient Register where diagnosis of diabetes occurred, or the earliest dispensation date of ATC code A10 from the Drug Register, whichever came first. Diabetes duration was not time-updated throughout the follow-up time due to collinearity with the time scale - attained age.

\section{Comorbidities}

To adjust for the effect of additional chronic diseases, we created a baseline comorbidity index as described by Charlson et al. [17], using the algorithm described by Quan et al. [18] as a weighted sum of diagnosed chronic disorders up to and including index date. In addition, the comorbidity index was updated after the index date, as the GLD exposure after dementia was time-updated (see section on Drug Register). The codes referring to the renal diseases were not included in the index but extracted and time updated as a separate adjustment/matching variable due to overall significant effect on GLD prescription. Diabetes variables were omitted from the index to avoid over-adjustment and the index was increased by one point for dementia patients.

\section{Longitudinal integrated database for health insurance and labour market studies (LISA)}

LISA is an administrative database covering the adult Swedish population since 1990 and provides high-quality information on sick leave, disability pensions, education, income and other socioeconomic characteristics [19].

\section{Disposable income}

To adjust for socioeconomic position, baseline individual disposable income at the time of index date inflated on the 2019 value of Consumer Price Index was extracted from LISA and categorized into low, middle, and high-income groups with 33rd and 66th percentiles used as cut-offs.

\section{Swedish prescribed drug register}

The Drug Register was established in 2005 and includes data on all dispensed drug prescriptions at Swedish pharmacies as coded by the Anatomical Therapeutic and Chemical (ATC) classification [20]. Medication dispensation data (=prescription fills) were extracted from the start of the register until December 31, 2018. 


\section{Diabetes mellitus}

ATC codes A10 (drugs used in diabetes), A10A (insulins), and A10B (blood glucose lowering drugs excluding insulin) before and after the index date extracted from the Drug Register were used in combination with the Patient Register to identify overall diabetes prevalence and duration and to classify diabetes types (see Supplementary Algorithm 1).

\section{Glucose-lowering drug exposure}

In addition to overall GLD use, seven specific GLD classes were extracted from the Drug Register according to following ATC codes: insulin (A10A), metformin (A10BA02), sulfonylurea derivates (SU) (A10BB), thiazolidinediones (TZDs) (A10BG), dipeptidyl-peptidase-4 inhibitors (DPP-4i; A10BH), glucagon-like peptide-1 analogues (GLP1a; A10BJ) and sodium-glucose co-transporter-2 inhibitors (SGLT-2i; A10BK). To determine baseline exposure (=at index date), we extracted the information on GLD dispensation in individual years prior to and including the index date (=dementia diagnosis date in the dementia cohort) (e.g., insulin dispensation in the one-year period prior to and including the index date). For time-updated exposure, we also extracted the first date of GLD dispensation in the yearly intervals after the index date (e.g., for the interval index date +2 years, first dispensation date in the interval between index date +365 days $\&$ index date +730 days was extracted). As-treated and intention-to-treat exposure models were used in analyses.

In the as-treated user versus non-user approach, baseline new users and non-users of individual medications were identified. New users were subjects who had dispensation of the medication for the first time in the one-year period prior to and including the index date and had no history of the medication use prior to the one-year period. The non-users were subjects with no dispensation of the studied medication prior to and including the index date. Afterwards, the drug exposure was time-updated according to presence or absence of first dispensation dates within yearly intervals after the index date. Specifically, the patients were considered exposed if a first dispensation date (start date for the interval) was present in the individual yearly intervals, with exposure lasting until the first dispensation date in the next yearly interval (with exposure continuing in the following interval). To take into account refilling of prescriptions and stockpiling of medications, patients were also kept exposed for 1 year after the last known dispensation date and then transferred to unexposed group if no next dispensation was observed. Also, patients were transferred to the exposed group if they had dispensation after an unexposed period. Conversely, if the patient had not been exposed at baseline and had no dispensation date after the index date, the patient was considered unexposed until the study end. We have used this approach previously in the setting of cholinesterase inhibitors [21], and provide a summary in the Supplementary Figure 2.

Secondly, intention-to-treat approach was used for user versus non-user analyses as well as user versus user comparisons. In the user versus non-user analyses, baseline new users and non-users of individual medications were identified identically to the as-treated model; however, the medication use was not time-updated.

Moreover, to compare non-metformin drug-drug effectiveness, we extracted subjects who were new users of one medication at index date without having dispensation of another medication prior to index date. For example, to compare insulin versus sulfonylurea, we identified insulin new users who were not exposed to sulfonylurea prior to index date and sulfonylurea new users who were not exposed to insulin prior to index date. Due to sample size limitations, only insulin versus sulfonylurea, DPP-4i versus sulfonylurea, and DPP-4i versus insulin comparisons were meaningful.

Due to too few new-users, TZD use was not analyzed but adjusted for in the models.

The exposure groups are summarized in the Table 2.

\section{Supplementary medication}

Baseline dispensations of antihypertensive (ATC codes $\mathrm{C} 02$, C07, C08, C09), diuretic (C03), hypolipidemic (statins, C10AA), antithrombotic (B01), antipsychotic (N05A), antidepressant drugs (N06A), and cholinesterase inhibitors (N06DA) were extracted up to three years prior to and including the index date as recorded by the Drug Register. The data on dispensation was also updated after the index date, based on presence/absence of dispensation within the one-year period preceding the start date of each exposure interval as described in the section on antidiabetic drug exposure. To avoid interference with the baseline assignment, time-updated exposure in the first year after index date had the same value as baseline exposure. 


\section{Swedish cause of death register (Death Register)}

The records in the Death Registry begin from the year 1952 and are the basis for official statistics on causes of death in Sweden [22]. The purpose of the registry is to describe the development of national all-cause and specific-cause mortality.

\section{Mortality}

We extracted the information from the Death Registry since its initiation until December 31, 2018, the end of the study follow-up. Overall mortality was considered if a valid record (patient death dated after index date) was present. The total amount of deaths in each analytic cohort is summarized in Table 2.

\section{Statistical analysis}

Eligible subjects were first matched on dementia status (Supplementary List 1), then the dementia and dementia-free cohorts were separately analyzed using new-user as-treated and intention-to-treat approaches. The aim of the as-treated model was to assign the time exposed to medication as precisely as possible, while the intention-to-treat models were used for comparative drug-to-drug analyses and concordance. Marginal structural models and PSmatching on exposure were employed to account for differences between the exposure groups.

\section{As-treated approach}

Due to presence of baseline and time-dependent confounding, marginal structural models using inverse-probability weighting were employed in the as-treated approach [23]. We followed the algorithm described by Fewell et al. [24], and created stabilized inverse-probability of treatment and censoring weights that represented each patient's observed antidiabetic treatment history and uncensored history. Compared to Fewell and colleagues, we analyzed the data with weighted flexible parametric survival model [25], using subject-specific time-varying weights. In dementia-free subjects the variables used to derive the weights comprised baseline-only (age at index date, sex, income category, diabetes type and duration) and time-updated characteristics (Charlson comorbidity index, renal failure, antihypertensive, diuretic, antithrombotic, antipsychotic and antidepressant drugs, other antidiabetic medications dispensed prior to and including the index date). In patients with dementia, baseline-only variables further included dementia diagnosis, MMSE value and cohabitation and time-updated variables also included cholinesterase inhibitors. These variables were chosen based on prognostic value and subjectmatter knowledge. The main characteristics of the stabilized weights are summarized in the Supplementary Table 4.

\section{Intention-to-treat approach}

To address baseline confounding in the intentionto-treat cohorts, we used 1:1 and 1:4 nearest neighbor PS-matching on baseline exposure of individual GLDs and drug-drug cohorts, in the parallel dementia and dementia-free cohorts. The matching variables were identical to the variables used to derive stabilized weights in the as-treated approach, however only values measured at baseline were used. Number of matching variables was restricted in some analyses due to sample size (Supplementary Table 6).

Table 2 comprises the user/non-user and user/ user cohorts used to analyze the effect of GLD on mortality.

\section{Descriptive statistics}

Differences in baseline characteristics between the dementia - dementia-free as well as the users and non-users within the respective dementia and dementia-free cohorts were assessed using chisquare, independent samples $t$-test and ANOVA, and their non-parametric equivalents. Standardized mean differences (SMDs) were used to assess balance in the propensity-score matched cohorts.

\section{Survival analyses}

We analyzed all-cause mortality in user versus nonuser and user versu user comparisons in the separate dementia and dementia-free cohorts. Hazard ratios (HR) for GLD usage were determined using flexible parametric survival models with four degrees of freedom for the restricted cubic splines. GLD exposure was time-varying in the as-treated approach and time-constant in the intention-to-treat analyses. Allcause mortality until the study end was the event of interest and attained age was used as time scale in all analyses. Kaplan-Meier survival and hazard curves were generated for the intention-to-treat PS-matched analyses. Variable-time interactions were introduced to the model to test the proportionality of hazards assumption. Statistical significance was determined using $p$-values and $95 \%$ confidence intervals (CI). Subjects with missing information in matching or 
weighting variables were excluded prior to analysis (see Supplementary Figure 1).

Data were analyzed using Stata v16 (Stata Statistical Software: Release 16. StataCorp LLC, College Station, TX) and R version 4.0.0 [26] with packages "MatchIt" and "rstpm2".

The whole analytical process is visualized in Supplementary Figure 3 with sulfonylurea as example. Concurrent use of GLDs in the respective analytical models is summarized in Supplementary Table 7.

\section{Ethical considerations}

Specific ethical approval was acquired before the project was carried out. After anonymization by the government agencies, the researchers were provided only with de-identified merged data and no link could be made to an individual. Study complies with the Declaration of Helsinki and was approved by the regional ethical committee in Stockholm, Sweden (number of the ethical approval: 2017/501-31).

\section{RESULTS}

Within the parallel dementia and dementia-free cohorts, some baseline differences were significant among GLD users/non-users in the as-treated approach (Table 1). PS-matching on exposure produced well-balanced intention-to-treat cohorts (Supplementary Tables 2 and 3).

\section{Mortality associated with glucose-lowering drugs}

The hazard ratios for the association between GLD use and mortality are summarized in Table 3.

In the as-treated model, metformin users had lower mortality in dementia-free $(0.75$ [0.61-0.91]), but not in dementia patients $(0.92$ [0.74-1.13]). Conversely, insulin was associated with higher mortality in both dementia (1.34 [1.23-1.45]) and dementia-free (1.54 [1.39-1.71]), respectively. Sulfonylureas were associated with $19 \%$ (1.19 [1.01-1.42]) higher mortality in dementia patients. DPP-4i use was survival-neutral in dementia patients $(1.04[0.90-1.20])$ and protective in dementia-free $(0.71$ [0.60-0.83]). On the other hand, GLP-1a were associated with lower mortality in the dementia cohort (0.44 [0.25-0.78]), while the hazard ratio was similar in dementiafree but did not reach statistical significance $(0.68$ [0.41-1.10]). Lastly, SGLT-2i use was associated with $57 \%$ lower mortality in new users with dementia
(0.43 [0.23-0.80]). No statistically significant association was found for SGLT-2i in the dementia-free subjects (Table 3 ).

In the intention-to-treat user versus non-user models, only SGLT-2i showed a reduced mortality in dementia patients $(0.29$ [0.09-0.91]) while among dementia-free metformin was associated with lower $(0.66[0.52-0.84])$ and insulin with higher mortality (1.22 [1.02-1.45]). Metformin was associated with lower mortality in the dementia cohort, however, not reaching the statistically significant threshold $(0.85$ [0.71-1.00], $p=0.051)$ ).

In the intention-to-treat drug-to-drug comparisons, no medication showed significantly mortality in dementia patients, while insulin was associated with higher mortality compared to sulfonylurea (1.44 [1.01-2.06]), and DPP-4i users had lower mortality compared to insulin users (0.64 [0.43-0.97]). Supplementary Figure 4 summarizes differences in survival and hazard.

\section{DISCUSSION}

In this large cohort of patients with diabetes, insulin use was associated with higher mortality, in both dementia and dementia-free subjects. Sulfonylurea users with dementia experienced higher mortality and GLP-1a and SGLT-2i use was protective among patients with dementia. Lastly, we observed a reduced mortality associated with metformin and DPP-4i use in dementia-free, while a similar reduction was not observed in patients with dementia.

Compared to non-users, the exposure to metformin was associated with $25 \%$ lower mortality in the astreated dementia-free group, while the direction of the association was similar, the mortality was not significantly lower in the metformin-treated dementia subjects. The findings from dementia-free concur with the mortality reductions observed in the metaanalysis by Campbell and colleagues' [27]; however, the relative lack of effect in dementia patients should be explained. One of the possible explanations may be in the differences in co-treatment with other GLDs in dementia and dementia-free, as dementia patients using metformin were frequently co-treated with insulin (70\%) compared to dementiafree $(52 \%)$ in the as-treated models. This argument is strengthened by the intention-to-treat analysis, where metformin's protective effect was stronger, albeit borderline insignificant, and the discrepancy between co-treatment with insulin was less pronounced (19\% 
Table 1

Baseline differences in as-treated exposure groups of individual glucose-lowering drugs by dementia status

\begin{tabular}{|c|c|c|c|c|c|c|c|c|c|}
\hline & \multicolumn{8}{|c|}{ Dementia cohort - baseline exposure as-treated cohorts } & \multirow[b]{2}{*}{$p$} \\
\hline & $\begin{array}{c}\text { Metformin Yes } \\
(n=573)\end{array}$ & $\begin{array}{c}\text { Metformin No } \\
(3,389)\end{array}$ & $p$ & $\begin{array}{c}\text { Insulin Yes } \\
(504)\end{array}$ & $\begin{array}{c}\text { Insulin No } \\
(6,985)\end{array}$ & $p$ & $\begin{array}{l}\text { SU Yes } \\
(190)\end{array}$ & $\begin{array}{l}\text { SU No } \\
(7,496) \\
\end{array}$ & \\
\hline Age, y & $78.1(7.6)$ & $81.5(7.0)$ & $<0.001$ & $80.0(7.0)$ & $80.2(7.6)$ & 0.43 & $79.3(7.1)$ & $79.4(7.2)$ & 0.82 \\
\hline Female & $280(48.9)$ & $1,583(46.7)$ & 0.34 & $247(49.0)$ & $3,260(46.7)$ & 0.31 & $88(46.3)$ & $3,604(48.1)$ & 0.63 \\
\hline MMSE & $21(7)$ & $21(7)$ & 0.21 & $21(7)$ & $21(6)$ & 0.30 & $21(6)$ & $21(6)$ & 0.70 \\
\hline Living alone & $210(36.6)$ & $1,503(44.3)$ & $<0.001$ & $212(42.1)$ & $2,992(42.8)$ & $<0.001$ & $77(40.5)$ & $3,124(41.7)$ & 0.82 \\
\hline Institutionalized & $45(7.9)$ & $380(11.2)$ & & $67(13.3)$ & $576(8.2)$ & & $20(10.5)$ & $691(9.2)$ & \\
\hline Diabetes duration, y & $1.0(4.2)$ & $6.3(6.8)$ & $<0.001$ & $6.4(7.3)$ & $6.1(6.0)$ & 0.23 & $3.3(6.6)$ & $6.5(6.8)$ & $<0.001$ \\
\hline Charlson comorbidity index & $2(2)$ & $2(2)$ & $<0.001$ & $2(3)$ & $2(2)$ & $<0.001$ & $2(2)$ & $2(2)$ & 0.008 \\
\hline Renal disease & $8(1.4)$ & $312(9.2)$ & $<0.001$ & $54(10.7)$ & $288(4.1)$ & $<0.001$ & $11(5.8)$ & $470(6.3)$ & 0.79 \\
\hline Antihypertensives & $419(73.1)$ & $2,585(76.3)$ & 0.10 & $411(81.5)$ & $5,392(77.2)$ & 0.024 & $144(75.8)$ & $5,893(78.6)$ & 0.35 \\
\hline Diuretics & $249(43.5)$ & $1,756(51.8)$ & $<0.001$ & $284(56.3)$ & $3,098(44.4)$ & $<0.001$ & $90(47.4)$ & $3,673(49.0)$ & 0.66 \\
\hline Statins & $349(60.9)$ & $1,979(58.4)$ & 0.26 & 337 (66.9) & $4,483(64.2)$ & 0.22 & $123(64.7)$ & $5,018(66.9)$ & 0.52 \\
\hline Antithrombotic drugs & $372(64.9)$ & $2,534(74.8)$ & $<0.001$ & $374(74.2)$ & $5,015(71.8)$ & 0.25 & $133(70.0)$ & $5,530(73.8)$ & 0.24 \\
\hline Antipsychotics & $28(4.9)$ & $254(7.5)$ & 0.025 & $35(6.9)$ & $448(6.4)$ & 0.64 & $8(4.2)$ & $533(7.1)$ & 0.12 \\
\hline Antidepressants & $187(32.6)$ & $1,215(35.9)$ & 0.14 & $166(32.9)$ & $2,510(35.9)$ & 0.18 & $57(30.0)$ & $2,796(37.3)$ & 0.04 \\
\hline Cholinesterase inhibitors & $65(11.3)$ & $324(9.6)$ & 0.19 & $39(7.7)$ & $792(11.3)$ & 0.013 & $22(11.6)$ & $789(10.5)$ & 0.64 \\
\hline Other GLDs & $172(30.0)$ & $1,750(51.6)$ & $<0.001$ & $434(86.1)$ & $5,340(76.4)$ & 0.02 & $138(72.6)$ & $5,851(78.1)$ & 0.08 \\
\hline \multicolumn{10}{|l|}{ Income category } \\
\hline Low & $174(30.4)$ & $1,017(30.0)$ & 0.44 & $160(31.7)$ & $2,055(29.4)$ & 0.22 & $65(34.2)$ & $2,197(29.3)$ & 0.07 \\
\hline \multirow[t]{2}{*}{ High } & $216(37.7)$ & $1,202(35.5)$ & & $167(33.1)$ & $2,580(36.9)$ & & $54(28.4)$ & $2,731(36.4)$ & \\
\hline & $\begin{array}{l}\text { DPP-4i Yes } \\
(230)\end{array}$ & $\begin{array}{c}\text { DPP-4i No } \\
(10,526)\end{array}$ & $p$ & $\begin{array}{c}\text { GLP-1a Yes } \\
(40)\end{array}$ & $\begin{array}{l}\text { GLP-1a No } \\
(11,203)\end{array}$ & $p$ & $\begin{array}{c}\text { SGLT-2i Yes } \\
(51)\end{array}$ & $\begin{array}{c}\text { SGLT-2i No } \\
(11,282)\end{array}$ & $p$ \\
\hline Age, & $79.7(7.0)$ & $79.8(7.1)$ & 0.79 & $75.7(7.0)$ & $79.9(7.1)$ & $<0.001$ & $75.7(6.3)$ & $79.8(7.1)$ & $<0.001$ \\
\hline Female & $103(44.8)$ & $5,088(48.3)$ & 0.29 & $20(50$ & 5,499 & 0.88 & 27 & $5,496(48.7)$ & 0.55 \\
\hline MMSE & $21(6.3)$ & $21(6)$ & 0.51 & $22(8)$ & $21(6)$ & 0.38 & $23(6)$ & $21(6)$ & $<0.001$ \\
\hline Living alone & $96(41.7)$ & $4,365(41.5)$ & 0.40 & $18(45.0)$ & $4,659(41.6)$ & 0.64 & $19(37.3)$ & $4,686(41.5)$ & 0.71 \\
\hline Institutionalized & $27(11.7)$ & $974(9.3)$ & & $5(12.5)$ & $1,042(9.3)$ & & $4(7.8)$ & $1,048(9.3)$ & \\
\hline Diabetes duration, y & $9.0(7.1)$ & $7.3(6.4)$ & $<0.001$ & $12.1(3.6)$ & $7.4(6.4)$ & $<0.001$ & $10.8(6.9)$ & $7.5(6.5)$ & $<0.001$ \\
\hline Charlson comorbidity index & $2(2.25)$ & $2(2)$ & 0.22 & $2(2)$ & $2(2)$ & 0.90 & $2(2)$ & $2(2)$ & 0.64 \\
\hline Renal disease & $30(13.0)$ & $674(6.4)$ & $<0.001$ & $5(12.5)$ & $746(6.7)$ & 0.14 & $1(2.0)$ & $766(6.8)$ & 0.26 \\
\hline Antihypertensives & $196(85.2)$ & $8,340(79.2)$ & 0.027 & $34(85.0)$ & $8,925(79.7)$ & 0.40 & $42(82.4)$ & $8,998(79.8)$ & 0.65 \\
\hline Diuretics & $125(54.3)$ & $5,094(48.4)$ & 0.07 & $26(65.0)$ & $5,417(48.4)$ & 0.035 & $20(39.2)$ & $5,483(48.6)$ & 0.18 \\
\hline Statins & $179(77.8)$ & $7,023(66.7)$ & $<0.001$ & $35(87.5)$ & $7,541(67.3)$ & 0.007 & $38(74.5)$ & $7,611(67.5)$ & 0.28 \\
\hline Antithrombotic drugs & 177( & $7,804(74.1)$ & 0.033 & & 8,323 & & 40( & $8,384(74.3)$ & 0.50 \\
\hline Antipsychotics & & & & & & & & 768 & 0.77 \\
\hline Antidep & 7) & $6)$ & 0.13 & & 4,0 & 0.2 & $20(3$ & $4,104(36.4)$ & 0.67 \\
\hline Cholinesterase inhibitors & $27(11.7)$ & $1,097(10.4)$ & 0.52 & $5(12.5)$ & $1,171(10.5)$ & 0.60 & $5(9.8)$ & $1,179(10.5)$ & 0.88 \\
\hline Other GLDs & $212(92.2)$ & $8,881(84.4)$ & $<0.001$ & $39(97.6)$ & $9,556(85.3)$ & 0.024 & $50(98.0)$ & $9,635(85.4)$ & 0.011 \\
\hline \multicolumn{10}{|l|}{ Income category } \\
\hline Low & $72(31.3)$ & $3,164(30.1)$ & 0.90 & $6(15.0)$ & $3,323(29.7)$ & 0.002 & $14(27.5)$ & $3,346(29.7)$ & 0.76 \\
\hline \multirow[t]{3}{*}{ High } & $82(35.7)$ & $3,754(35.7)$ & & $10(25.0)$ & $4,047(36.1)$ & & $17(33.3)$ & $4,070(36.1)$ & \\
\hline & \multicolumn{9}{|c|}{ Dementia-free cohort - baseline exposure as-treated cohorts } \\
\hline & $\begin{array}{c}\text { Metformin Yes } \\
\text { (471) }\end{array}$ & $\begin{array}{c}\text { Metformin No } \\
(3,491)\end{array}$ & $p$ & $\begin{array}{c}\text { Insulin Yes } \\
(483)\end{array}$ & $\begin{array}{c}\text { Insulin No } \\
(7,006)\end{array}$ & $p$ & $\begin{array}{c}\text { SU Yes } \\
(170)\end{array}$ & $\begin{array}{l}\text { SU No } \\
(7,516)\end{array}$ & $p$ \\
\hline Age, $y$ & $76.3(7.1)$ & $81.7(7.0)$ & $<0.001$ & $81(6.7)$ & $79.8(7.2)$ & $<0.001$ & $77.3(7.4)$ & $79.4(7.4)$ & $<0.001$ \\
\hline Female & $243(51.6)$ & $1,636(46.9)$ & 0.05 & $246(50.9)$ & $3,199(45.7)$ & 0.025 & $81(47.6)$ & $3,617(48.1)$ & 0.90 \\
\hline Diabetes duration, y & $6.4(6.9)$ & $1.0(2.7)$ & $<0.001$ & $6.2(7.0)$ & $6.3(6.0)$ & 0.11 & $4.1(5.6)$ & $6.7(6.6)$ & $<0.001$ \\
\hline Charlson comorbidity index & $1(2)$ & $2(3)$ & $<0.001$ & $2(3)$ & $2(3)$ & $<0.001$ & $2(3)$ & $2(2)$ & 0.42 \\
\hline Renal disease & $4(0.8)$ & $321(9.2)$ & $<0.001$ & $50(10.4)$ & $293(4.2)$ & $<0.001$ & $4(2.4)$ & $454(6.0)$ & 0.045 \\
\hline Antihypertensives & $346(73.5)$ & $2,747(78.7)$ & & $389(80.5)$ & $5,495(78.4)$ & 0.28 & $124(72.9)$ & $5,923(78.8)$ & 0.07 \\
\hline Diuretics & $194(41.2)$ & $1,768(50.6)$ & $<0.001$ & $275(56.9)$ & $2,873(41.0)$ & $<0.001$ & $77(45.3)$ & $3,524(46.9)$ & 0.68 \\
\hline Statins & $309(65.6)$ & $2,142(61.4)$ & 0.08 & $321(66.5)$ & $4,712(67.3)$ & 0.72 & $119(70.0)$ & $5,283(70.3)$ & 0.94 \\
\hline Antithrombotic drugs & $287(60.9)$ & $2,600(74.5)$ & $<0.001$ & $374(77.4)$ & $5,046(72.0)$ & 0.01 & $111(65.3)$ & $5,572(74.1)$ & 0.009 \\
\hline Antipsychotics & $15(3.2)$ & $197(5.6)$ & 0.026 & $32(6.6)$ & $356(5.1)$ & 0.14 & $12(7.1)$ & $447(5.9)$ & 0.55 \\
\hline Antidepressants & $125(26.5)$ & $1,216(34.8)$ & $<0.001$ & $185(38.3)$ & $2,567(36.6)$ & 0.46 & $55(32.4)$ & $2,848(37.9)$ & 0.14 \\
\hline Other GLDs & $110(23.4)$ & $1,713(49.1)$ & $<0.001$ & $398(82.4)$ & $5,456(77.9)$ & $<0.001$ & $133(78.2)$ & $5,925(78.8)$ & 0.85 \\
\hline \multicolumn{10}{|l|}{ Income category } \\
\hline Low & $101(21.4)$ & $986(28.2)$ & $<0.001$ & $154(31.9)$ & $1,965(28.0)$ & 0.08 & $47(27.6)$ & $2,106(28.0)$ & 0.15 \\
\hline High & $225(47.8)$ & $1,324(37.9)$ & & $161(33.3)$ & $2,668(38.1)$ & & $76(44.7)$ & $2,861(38.1)$ & \\
\hline
\end{tabular}


Table 1

(Continued)

\begin{tabular}{|c|c|c|c|c|c|c|c|c|c|}
\hline & $\begin{array}{l}\text { DPP-4i Yes } \\
\quad(234)\end{array}$ & $\begin{array}{c}\text { DPP-4i No } \\
(10,522)\end{array}$ & $p$ & $\begin{array}{c}\text { GLP-1a Yes } \\
\text { (36) }\end{array}$ & $\begin{array}{c}\text { GLP-1a No } \\
(11,207)\end{array}$ & $p$ & $\begin{array}{c}\text { SGLT-2i Yes } \\
(45)\end{array}$ & $\begin{array}{c}\text { SGLT-2i No } \\
(11,282)\end{array}$ & $p$ \\
\hline Age, y & $78.5(7.4)$ & $79.8(7.2)$ & 0.005 & $72.7(8.1)$ & $79.8(7.2)$ & $<0.001$ & $75.5(7.2)$ & $79.7(7.3)$ & $<0.001$ \\
\hline Female & $113(48.3)$ & $5,077(48.3)$ & 0.99 & $16(44.4)$ & $5,462(48.7)$ & 0.61 & $23(51.1)$ & $5,405(47.9)$ & 0.67 \\
\hline Diabetes duration, y & $8.7(5.1)$ & $7.5(6.4)$ & $<0.001$ & $10.3(6.7)$ & $7.8(6.4)$ & 0.003 & $10.9(5.7)$ & $7.8(6.3)$ & $<0.001$ \\
\hline Charlson comorbidity index & $2(3)$ & $2(2)$ & 0.70 & $1(2)$ & $2(2)$ & 0.005 & $1(2)$ & $2(3)$ & $<0.001$ \\
\hline Renal disease & $24(10.3)$ & $708(6.7)$ & 0.034 & $1(2.8)$ & $741(6.6)$ & 0.73 & $0(0.0)$ & $734(6.5)$ & 0.12 \\
\hline Antihypertensives & $207(88.5)$ & $8,507(80.8)$ & 0.003 & $35(97.2)$ & $9,082(81.0)$ & 0.009 & $38(84.4)$ & $9,144(81.0)$ & 0.56 \\
\hline Diuretics & $112(47.9)$ & $4,923(46.8)$ & 0.74 & $12(33.3)$ & $5,237(46.7)$ & 0.11 & $16(35.6)$ & $5,283(46.8)$ & 0.13 \\
\hline Statins & $178(76.1)$ & $7,309(69.5)$ & 0.03 & $30(83.3)$ & $7,802(69.6)$ & 0.07 & $38(84.4)$ & $7,917(70.1)$ & 0.036 \\
\hline Antithrombotic drugs & 187 (79.9) & $7,849(74.6)$ & 0.064 & $21(58.3)$ & $8,376(74.7)$ & 0.024 & $28(62.2)$ & $8,428(74.7)$ & 0.06 \\
\hline Antipsychotics & $5(2.1)$ & $593(5.6)$ & 0.021 & $1(2.8)$ & $648(5.8)$ & 0.44 & $1(2.2)$ & $635(5.6)$ & 0.52 \\
\hline Antidepressants & $86(36.8)$ & $3,869(36.8)$ & 1.00 & $10(27.8)$ & $4,073(36.3)$ & 0.29 & 17 (37.8) & $4,192(37.1)$ & 0.92 \\
\hline Other GLDs & $222(94.9)$ & $8,876(84.4)$ & $<0.001$ & $36(100.0)$ & $9,562(85.3)$ & 0.013 & $45(100.0)$ & $9,712(86.0)$ & 0.007 \\
\hline \multicolumn{10}{|l|}{ Income category } \\
\hline Low & $59(25.2)$ & $3,029(28.8)$ & 0.35 & $8(22.2)$ & 3,129 (27.9) & 0.08 & 7 (15.6) & $3,220(28.5)$ & 0.16 \\
\hline High & $97(41.5)$ & $3,921(37.3)$ & & $20(55.6)$ & $4,204(37.5)$ & & $20(44.4)$ & 4,239 (37.6) & \\
\hline
\end{tabular}

Baseline characteristics were compared per baseline exposure assignment (new users without prior history of medication dispensation). DPP-4i, dipeptidyl-peptidase-4 inhibitors; GLP-1a, glucagon-like peptide-1 agonists; SGLT-2i, sodium-glucose cotransporter-2 inhibitors; MMSE, Mini-Mental State Examination. $p$-values refer to the exposure "Yes" versus exposure "No" comparisons. Number of exposed does not include subjects who became exposed after baseline. Due to space constraints, the distributions of dementia diagnoses are summarized in Supplementary Table 3. Age is described as mean (SD). Charlson comorbidity index, Diabetes duration, and MMSE are described as median (IQR); all other variables are described as $n(\%)$.

dementia versus $17 \%$ dementia-free). While we did not assess whether insulin mediated some mortality risk among metformin users, the notion seems plausible, especially as insulin use was associated with higher mortality risk in both cohorts. On the other hand, some animal studies suggest that in $A P O E$ $\varepsilon 4$ carriers with manifest dementia, metformin may even contribute to further neurodegeneration [28, 29], which could counteract the pro-survival properties observed in the dementia-free cohort. Further research is necessary to confirm such hypothesis, as we did not have access to genetic data.

Overall, despite the neutral effect on survival in our cohort, metformin's position as first line diabetes therapy seems valid in patients with dementia.

Insulin was frequently used throughout the follow-up and prescribed relatively early (median 6 years diabetes duration at baseline), a reflection of Sweden's approach to type 2 diabetes care [30-32]. Interestingly, though the cohorts were not directly compared, the mortality among patients with dementia was lower than in dementia-free, and insulin-associated mortality was similar to both sulfonylurea and DPP-4i, despite its propensity for hypoglycemia [33]. Conversely, insulin treatment negatively affected survival in all analyses among the dementia-free. While some observational studies have reported higher insulin-associated mortality $[34,35]$, the data from randomized trials did not confirm such association [8]. Gamble has suggested that the discordant results likely stem from the intermediating effect of biochemical and clinical variables confounding the association in observational studies [36]. Despite applying marginal structural models for time-dependent confounding, we lacked information on glycemia or weight, thus the bias may extend to our study. Cognitive functioning is an important factor for insulin administration; however, the insulin-associated mortality was comparable in dementia and dementia-free, even neutral in the intention-to-treat analysis among dementia patients. Importantly, patients with diabetes and dementia in Sweden receive nursing assistance with insulin applications, thus providing additional check-up and minimizing the effect of cognitive decline on proper self-management. Second, insulin-connected weight increase may have stabilizing effects in patients with dementia, where weight loss is a common symptom [37]. Lacking data on HbA1c, we could not determine whether insulin treatment would control hyperglycemia while avoiding major hypoglycemic events, conversely the absence of substantial mortality increase between dementia and dementia-free supports the use of insulin even in patients with manifest cognitive problems.

Conversely, sulfonylurea derivates were associated with modest mortality increase, however, only in patients with dementia. Sulfonylureas are an effective 
Table 2

Number of events (death), exposure groups and person-time assigned in the as-treated and intention-to-treat models

\begin{tabular}{|c|c|c|c|c|c|c|c|c|c|}
\hline & \multicolumn{6}{|c|}{ As-treated analyses } & \multicolumn{3}{|c|}{ Intention-to-treat analyses } \\
\hline & $\begin{array}{l}\text { Baseline } \\
\text { exposed }\end{array}$ & $\begin{array}{c}\text { Total } \\
\text { exposed } \\
\text { (baseline or } \\
\text { follow-up) }\end{array}$ & $\begin{array}{l}\text { Baseline } \\
\text { unexposed }\end{array}$ & $\begin{array}{l}\text { Total } \\
\text { unexposed } \\
\text { (baseline or } \\
\text { follow-up) }\end{array}$ & $\begin{array}{l}\text { N events, } \\
\text { total }\end{array}$ & $\begin{array}{l}\text { Person-time } \\
\text { at risk, } \\
\text { total y }\end{array}$ & $\begin{array}{c}\text { PS- } \\
\text { Matched } \\
\text { exposed / } \\
\text { unexposed }\end{array}$ & $\begin{array}{l}\text { N events, } \\
\text { exposed / } \\
\text { unexposed }\end{array}$ & $\begin{array}{l}\text { Person-time } \\
\text { at risk, } \\
\text { total y }\end{array}$ \\
\hline & \multicolumn{9}{|c|}{ Patients with dementia } \\
\hline $\begin{array}{l}\text { Metformin }(3,962 \\
\text { eligible })\end{array}$ & $573(14.4 \%)$ & $960(24.2 \%)$ & $3,389(85.6 \%)$ & $3,002(75.8 \%)$ & $2,348(59.2 \%)$ & $12,707.8$ & $478 / 478$ & $237 / 276$ & $3,399.0$ \\
\hline Insulin $(7,489)$ & $504(6.7 \%)$ & $1,876(25.1 \%)$ & $6,985(93.3 \%)$ & $5,613(74.9 \%)$ & $3,775(50.4 \%)$ & $24,370.4$ & $496 / 496$ & $275 / 256$ & $3,211.4$ \\
\hline SU $(7,686)$ & $190(2.5 \%)$ & $449(5.8 \%)$ & $6,985(97.5 \%)$ & $7,237(94.2 \%)$ & $3,829(49.8 \%)$ & $24,621.0$ & 190/190 & $106 / 88$ & $1,446.9$ \\
\hline DPP-4i $(10,756)$ & $230(2.1 \%)$ & $1,003(9.3 \%)$ & $10,526(97.9 \%)$ & $9,753(90.7 \%)$ & $5,714(53.1 \%)$ & $34,946.6$ & $230 / 230$ & $80 / 126$ & $1,256.9$ \\
\hline GLP-1a $(11,243)$ & $40(0.4 \%)$ & $165(1.5 \%)$ & $11,203(99.6 \%)$ & $11,078(98.5 \%)$ & $5,869(52.2 \%)$ & $36,083.3$ & $39 / 155$ & $5 / 66$ & 507.6 \\
\hline \multirow[t]{2}{*}{ SGLT-2i $(11,333)$} & $51(0.5 \%)$ & $194(1.7 \%)$ & $11,282(99.5 \%)$ & $11,139(98.3 \%)$ & $5,896(52.0 \%)$ & $36,331.3$ & $51 / 201$ & $3 / 84$ & 733.1 \\
\hline & \multicolumn{9}{|c|}{ Dementia-free patients } \\
\hline $\begin{array}{l}\text { Metformin }(3,962 \\
\text { eligible })\end{array}$ & $471(11.9 \%)$ & $824(20.8 \%)$ & $3,491(88.1 \%)$ & $3,138(79.2 \%)$ & $1,997(50.4 \%)$ & $11,984.5$ & $326 / 326$ & $125 / 153$ & $2,406.6$ \\
\hline Insulin $(7,489)$ & $483(6.4 \%)$ & $1,577(21.1 \%)$ & $7,006(93.6 \%)$ & $5,912(78.9 \%)$ & $2,927(39.1 \%)$ & $23,693.9$ & $481 / 481$ & $270 / 223$ & $2,790.6$ \\
\hline $\mathrm{SU}(7,686)$ & $170(2.2 \%)$ & $442(5.8 \%)$ & $7,516(97.8 \%)$ & $7,244(94.2 \%)$ & $3,066(39.9 \%)$ & $23,585.6$ & $169 / 169$ & $71 / 58$ & $1,197.9$ \\
\hline DPP-4i $(10,756)$ & $234(2.2 \%)$ & $1,100(10.2 \%)$ & $10,522(97.8 \%)$ & $9,656(90.8 \%)$ & $4,752(44.2 \%)$ & $33,197.5$ & $233 / 233$ & $66 / 83$ & $1,413.2$ \\
\hline GLP-1a $(11,243)$ & $36(0.3 \%)$ & $271(2.4 \%)$ & $11,207(99.7 \%)$ & $10,972(97.6 \%)$ & $4,735(42.1 \%)$ & $34,804.0$ & $35 / 137$ & $4 / 38$ & 594.2 \\
\hline \multirow[t]{3}{*}{ SGLT-2i $(11,333)$} & $45(0.4 \%)$ & $342(3.0 \%)$ & $11,282(99.6 \%)$ & $10,991(97.0 \%)$ & $4,853(42.8 \%$ & $34,528.6$ & $45 / 180$ & $4 / 56$ & 632.1 \\
\hline & & & \multicolumn{3}{|c|}{$\begin{array}{l}\text { Comparative analyses } \\
\text { (intention-to-treat) - } \\
\text { Patients with dementia }\end{array}$} & \multicolumn{4}{|c|}{$\begin{array}{l}\text { Comparative analyses } \\
\text { (intention-to-treat) - } \\
\text { Dementia-free patients }\end{array}$} \\
\hline & & $\begin{array}{r}\text { All } \\
\text { baseli } \\
\text { users } \\
\text { user }\end{array}$ & $\begin{array}{c}\text { PS- } \\
\text { Matched } \\
\text { users / } \\
\text { users }\end{array}$ & $\begin{array}{c}\text { N events, } \\
\text { users / } \\
\text { users }\end{array}$ & $\begin{array}{l}\text { Person-time } \\
\text { at risk, } \\
\text { total } \\
\text { years }\end{array}$ & $\begin{array}{c}\text { All } \\
\text { baseline } \\
\text { users / } \\
\text { users }\end{array}$ & $\begin{array}{l}\text { PS- } \\
\text { Matched } \\
\text { users / } \\
\text { users } \\
\end{array}$ & $\begin{array}{c}\text { N events, } \\
\text { users / } \\
\text { users }\end{array}$ & $\begin{array}{l}\text { Person-time } \\
\text { at risk, } \\
\text { total } \\
\text { years }\end{array}$ \\
\hline \multicolumn{2}{|c|}{$\begin{array}{l}\text { Insulin versus SU (407 dementia - } \\
\text { dementia-free pairs) }\end{array}$} & $247 / 160$ & $135 / 135$ & $79 / 75$ & 930.7 & $234 / 173$ & $139 / 139$ & $67 / 61$ & 879.2 \\
\hline \multicolumn{2}{|c|}{ DPP-4i versus SU (291) } & \multirow{2}{*}{$\begin{array}{l}120 / 171 \\
126 / 424\end{array}$} & $81 / 81$ & $30 / 47$ & 495.4 & $128 / 163$ & $81 / 81$ & $18 / 32$ & 541.4 \\
\hline \multicolumn{2}{|c|}{ DPP-4i versus Insulin (551) } & & $123 / 123$ & $39 / 72$ & 708.3 & $166 / 384$ & $152 / 152$ & $34 / 67$ & 907.2 \\
\hline
\end{tabular}

SU, sulfonylurea derivates; DPP-4i, dipeptidyl-peptidase-4 inhibitors; GLP-1a, glucagon-like peptide-1 agonists; SGLT-2i, sodium-glucose cotransporter- 2 inhibitors. Number of events divided by exposure status in the as-treated groups are not provided as patients were allowed to enter and leave exposure groups; Events - all-cause deaths; Events, exposure and person-time at risk for intention-to-treat cohorts are summarized in Supplementary Table 2. All eligible subjects (eligible to be, e.g., new users, i.e., without history of medication use prior to index date) were first PS-matched on dementia status (e.g., metformin - 3,962 dementia - dementia-free pairs), and then either analyzed in as-treated models, or further propensity-score matched on baseline exposure in the parallel dementia and dementia-free cohorts and analyzed using intention-to-treat models. Comparative analyses were done in patients who were new users of one drug without having dispensation of the comparator drug prior to index date (and vice-versa). In PS-matching, priority was given to prognostic variables - see Supplementary Table 6 for the list of matching variables in all analyses. All standardized mean differences for the matching variables were $\leq 0.1$.

and inexpensive second-line therapy [5]; yet, hypoglycemia poses a non-negligible risk [4, 9]. Despite some inconsistencies, sulfonylureas did not increase all-cause mortality in the general type 2 diabetes population $[8,38]$ and the risk of bias among studies very much depend on the comparator and the outcome [39]. On the other hand, hypoglycemia may be particularly damaging to patients with dementia, where the associated cognitive damage results in inability to self-manage diabetes $[6,7]$. In conclusion, due to the increased mortality risk, continuous glucose monitoring may be a good option as dementia progresses if sulfonylureas are required.
Contrary to dementia-free, patients with dementia treated with DPP-4i did not experience lower mortality compared to non-users, and the injectable GLP-1a were only protective in patients with dementia. Importantly, compared to GLP-1a, the use of DPP-4i has increased significantly during the study follow-up, which probably reflects the neutral weight effects in DPP-4i (versus weight loss in GLP-1a) and the oral application method [5]. Interestingly, Palmer and colleagues concluded no effect on mortality in either GLP-1a or DPP-4i [8], while Longato and colleagues reported better survival and cardiovascular profile in GLP-1a compared to DPP-4i [40] 
Table 3

All-cause mortality risk associated with incident glucose-lowering drug usage by dementia status and type of analysis

\begin{tabular}{|c|c|c|c|c|}
\hline & & $\begin{array}{l}\text { Crude \& weighted } \\
\text { as-treated analyses }\end{array}$ & $\begin{array}{l}\text { Adjusted \& weighted } \\
\text { as-treated analyses }\end{array}$ & $\begin{array}{l}\text { PS-matched intention- } \\
\text { to-treat analyses }\end{array}$ \\
\hline & & \multicolumn{3}{|c|}{ Dementia patients, hazard ratio $(95 \% \mathrm{CI})$} \\
\hline & & $\begin{array}{l}\text { GLD user versus } \\
\text { GLD non-user }\end{array}$ & $\begin{array}{l}\text { GLD user versus } \\
\text { GLD Non-User }\end{array}$ & $\begin{array}{l}\text { GLD user versus } \\
\text { GLD Non-User }\end{array}$ \\
\hline \multirow{19}{*}{ 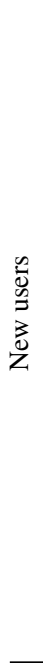 } & Metformin & $0.80(0.63-1.01)$ & $0.92(0.74-1.13)$ & $0.84(0.71-1.00)$ \\
\hline & Insulin & $1.32(1.22-1.42)^{\dagger}$ & $1.34(1.23-1.45) \dagger$ & $0.97(0.82-1.15)$ \\
\hline & SU & $1.11(0.93-1.33)$ & $1.19(1.01-1.42)^{*}$ & $1.14(0.86-1.51)$ \\
\hline & DPP-4i & $1.05(0.92-1.20)$ & $1.04(0.90-1.20)$ & $0.88(0.67-1.17)$ \\
\hline & GLP-1a & $0.48(0.27-0.86)^{*}$ & $0.44(0.25-0.78)^{*}$ & $0.48(0.19-1.20)$ \\
\hline & SGLT-2i & $0.36(0.19-0.71)^{*}$ & $0.43(0.23-0.80)^{*}$ & $0.29(0.09-0.91)^{*}$ \\
\hline & Insulin versus SU & & & $1.17(0.85-1.60)$ \\
\hline & DPP-4i versus SU & & & $1.13(0.71-1.79)$ \\
\hline & \multirow[t]{2}{*}{ DPP-4i versus Insulin } & & & $0.84(0.57-1.24)$ \\
\hline & & \multicolumn{3}{|c|}{ Dementia-free subjects, hazard ratio $(95 \% \mathrm{CI})$} \\
\hline & Metformin & $0.59(0.49-0.71)^{\dagger}$ & $0.75(0.61-0.91)^{*}$ & $0.77(0.61-0.98)^{*}$ \\
\hline & Insulin & $1.54(1.39-1.70)^{\dagger}$ & $1.54(1.39-1.71)^{\dagger}$ & $1.35(1.13-1.61)^{*}$ \\
\hline & SU & $0.88(0.67-1.15)$ & $1.00(0.77-1.32)$ & $1.07(0.76-1.52)$ \\
\hline & DPP-4i & $0.64(0.54-0.75)^{\dagger}$ & $0.71(0.60-0.83)^{\dagger}$ & $0.91(0.66-1.27)$ \\
\hline & GLP-1a & $0.59(0.36-0.97)^{*}$ & $0.68(0.41-1.10)$ & $0.65(0.23-1.83)$ \\
\hline & SGLT- $2 \mathrm{i}$ & $0.46(0.20-1.05)$ & $0.52(0.22-1.23)$ & $0.57(0.20-1.56)$ \\
\hline & Insulin versus SU & & & $1.45(1.02-2.06)^{*}$ \\
\hline & DPP-4i versus SU & & & $0.76(0.42-1.37)$ \\
\hline & DPP-4i versus Insulin & & & $0.64(0.43-0.97)^{*}$ \\
\hline
\end{tabular}

n.s., not significant; DPP-4i, dipeptidyl-peptidase-4 inhibitors; GLD, glucose-lowering drugs; GLP-1a, glucagonlike peptide-1 analogues; SGLT-2i, sodium-glucose cotransporter-2 inhibitors; SU, sulfonylureas. As-treated models were weighted using inverse-probability stabilized treatment and censoring weights. Crude model was weighted but not adjusted. Adjusted model in the dementia-free group included baseline sex, comorbidity index, renal failure, diabetes type \& duration, cardiovascular, antithrombotic, psychotropic and dementia medication, income and other GLD. Analysis in dementia patients were further adjusted for cohabitation, dementia type, and MMSE. Intention-to-treat analyses were PS-matched on baseline covariates, the list of variables for each matching is summarized in Supplementary Table 6. Flexible parametric survival models were used to determine the hazard ratios of antidiabetic drug usage and mortality. Drug-drug comparisons (e.g., Insulin versus SU) were done among new users of, e.g., insulin who were never exposed to sulfonylurea prior to index date compared to new users of sulfonylurea who were never exposed to insulin prior to index date. Number of users within each intention-to-treat group and variables included in the matching are summarized in Table 2 and Supplementary Table 6 . There were insufficient number of eligible subjects for other comparisons. ${ }^{*} p$-value $<0.05 ;{ }^{\dagger} p$-value $<0.001$.

and Nyström et al. found DPP-4i superior to insulin for survival [30]. While the comparison to insulin favored DPP-4i, the association was non-significant in our cohort. The lack of protection associated with DPP-4i therapy is curious; however, due to insulin's role as second-line therapy in Sweden [31] and more frequent use of insulin in Swedish patients with dementia [32], the neutral effect may reflect the late addition of DPP-4i (longer baseline diabetes duration among DPP-4i users) or well-controlled insulin therapy in patients with dementia. On the other hand, the GLP-1a were seldom prescribed and the cohort was probably selected to individuals where their weight-decreasing effect was desirable and injectable regimen was not a barrier. On the other hand, the effect size of GLP-1a in patients with dementia should encourage exploring wider use in these patients. Injections should not be a larger hindrance than insulin, especially when regimens with weekly applications are available [5] and the cardiovascular profile is favorable [41].

The exposure to SGLT-2i was associated with substantial decrease in mortality in patients with dementia; however, their prescription was infrequent. SGLT-2i have a very specific pharmacological profile with cardiovascular, renoprotective, and antihypertensive effects [5, 42]. Recently, Longato and colleagues have also concluded SGLT-2i superior to GLP-1a in reducing major cardiovascular events, with trends toward lower mortality [43]. Interestingly, Suissa has examined the immortal-time bias often introduced in observational studies of SGLT-2i, 
which potentially overestimated the protective effect of SGLT-2i [44]. True, the mortality reduction was larger compared to EMPA-REG OUTCOME trial [45]; however, the SGLT-2i users in our population had the longest baseline diabetes duration, which, logically should skew the results in an opposite direction (towards the null). While the significant effect was only found in new users with dementia, the overall protective trend was clear in all analyses. It is likely that the overall frailty of the cohort and less extensive research in the elderly could have mediated the SGLT-2i under-prescription, however this should not limit the SGLT-2i use in the future. Stratification on individual SGLT-2i agents in larger cohorts is needed to form a comprehensive picture.

\section{Strengths and limitations}

The study's main strength lies in the large cohort of dementia and dementia-free subjects, long follow-up (up to 12 years after index date) and high coverage across the main data sources [14, 15, 19, 20, 22]. SveDem's incident-case coverage was estimated at $36 \%$ in 2015 [11], which is likely underestimated due to Sweden's decreasing dementia incidence [46]. In addition, the new user design and time-updated exposure of all main GLD groups in combination with the accurate time-updated data on the major confounders greatly increases the study validity. Specifically, as patients' life experience evolves with time, the time-varying nature of drug exposure more closely reflects the clinical practice than the intention-to-treat approach. Indeed, we have evaluated both as-treated and intention-to-treat exposure approaches, showing the same direction, albeit not consistently significant results. Moreover, we have addressed the baseline and time-dependent confounding (using PS matching and inverse-probability weighting) to ensure a degree of comparability between dementia and dementiafree, and within the exposed and unexposed groups. Importantly, PS matching to sample dementia dementia-free pairs has been supplemented by exact matching on the index year, to minimize the effect of evolving diabetes guidelines, and the inverseprobability weighting reflects the unique experience the subjects had in the cohort based on baseline and time-updated characteristics.

On the other hand, due to the absence of clinical reasoning behind the prescriptions (confounding by indication) and the study's observational design we cannot conclude causal relationships. Importantly, dementia and dementia-free were analyzed in parallel and not directly compared, as we had more prognostic variables in the dementia cohort, which could not have been adjusted for in dementia-free. However, some degree of comparability can be claimed, as the subjects were strictly matched on dementia status. The duration of diabetes could have been underestimated (no primary care data); however, due to identical data extraction in all subjects, we have no reason to believe this error was differential in dementia versus dementia-free or users and non-users. Importantly, the Drug Register data were available only from 2005 , therefore some metformin, insulin, and sulfonylurea dispensations may have been missed. Conversely, the earliest dementia/index date was recorded in 2007, therefore we had minimum 2 years of prior dispensation data for all subjects. Unfortunately, none of the registers contained data on glycemia or other metabolic measures, and residual confounding was still present.

Overall, we believe the differences between the survival of patients with and without dementia bring important leads for pharmacological management of diabetes in a frail and understudied population.

\section{ACKNOWLEDGMENTS}

We would like to thank all patients, care providers and staff for providing the information to the Swedish Dementia Registry.

This study has been supported by the Swedish Research Council (grant numbers 2012-2291, 2016-02317, 2018-02843), Alzheimerfonden, Stockholm County Council (ALF project), Stockholm University, the Swedish Associations of Local Authorities and Regions, the Swedish Order of Saint John/Johanniterorden, Swedish Society for Medical Research, FORTE (the Swedish Council for Health, Working Life and Welfare, dnr: 2017-01646), the Swedish Stroke Association, Margaretha af Ugglas foundation and the Stiftelsen för Gamla Tjänarinnor.

Authors' disclosures available online (https:// www.j-alz.com/manuscript-disclosures/21-5337r1).

\section{SUPPLEMENTARY MATERIAL}

The supplementary material is available in the electronic version of this article: https://dx.doi.org/ 10.3233/JAD-215337. 


\section{REFERENCES}

[1] Bunn F, Burn AM, Goodman C, Rait G, Norton S, Robinson L, Schoeman J, Brayne C (2014) Comorbidity and dementia: A scoping review of the literature. BMC Med 12, 192.

[2] Secnik J, Cermakova P, Fereshtehnejad SM, Dannberg P, Johnell K, Fastbom J, Winblad B, Eriksdotter M, Religa D (2017) Diabetes in a large dementia cohort: Clinical characteristics and treatment from the Swedish Dementia Registry. Diabetes Care 40, 1159-1166.

[3] Livingston G, Sommerlad A, Orgeta V, Costafreda SG, Huntley J, Ames D, Ballard C, Banerjee S, Burns A, CohenMansfield J, Cooper C, Fox N, Gitlin LN, Howard R, Kales HC, Larson EB, Ritchie K, Rockwood K, Sampson EL, Samus Q, Schneider LS, Selbæk G, Teri L, Mukadam N (2017) Dementia prevention, intervention, and care. Lancet 390, 2673-2734.

[4] American Diabetes Association (2020) 12. Older Adults: Standards of Medical Care in Diabetes-2020. Diabetes Care 43, S152-S162.

[5] Davies MJ, D'Alessio DA, Fradkin J, Kernan WN, Mathieu C, Mingrone G, Rossing P, Tsapas A, Wexler DJ, Buse JB (2018) Management of hyperglycaemia in type 2 diabetes, 2018. A consensus report by the American Diabetes Association (ADA) and the European Association for the Study of Diabetes (EASD). Diabetologia 61, 24612498.

[6] Whitmer RA, Karter AJ, Yaffe K, Quesenberry CP, Jr., Selby JV (2009) Hypoglycemic episodes and risk of dementia in older patients with type 2 diabetes mellitus. JAMA 301, 1565-1572.

[7] Punthakee Z, Miller ME, Launer LJ, Williamson JD, Lazar RM, Cukierman-Yaffee T, Seaquist ER, Ismail-Beigi F, Sullivan MD, Lovato LC, Bergenstal RM, Gerstein HC, ACCORD Group of Investigators; ACCORD-MIND Investigators (2012) Poor cognitive function and risk of severe hypoglycemia in type 2 diabetes: Post hoc epidemiologic analysis of the ACCORD trial. Diabetes Care 35, 787-793.

[8] Palmer SC, Mavridis D, Nicolucci A, Johnson DW, Tonelli M, Craig JC, Maggo J, Gray V, De Berardis G, Ruospo M, Natale P, Saglimbene V, Badve SV, Cho Y, Nadeau-Fredette AC, Burke M, Faruque L, Lloyd A, Ahmad N, Liu Y, Tiv S, Wiebe N, Strippoli GF (2016) Comparison of clinical outcomes and adverse events associated with glucose-lowering drugs in patients with type 2 diabetes: A meta-analysis. JAMA 316, 313-324.

[9] Maruthur NM, Tseng E, Hutfless S, Wilson LM, SuarezCuervo C, Berger Z, Chu Y, Iyoha E, Segal JB, Bolen S (2016) Diabetes medications as monotherapy or metforminbased combination therapy for type 2 diabetes: A systematic review and meta-analysis. Ann Intern Med 164, 740-751.

[10] Fei Y, Tsoi MF, Cheung BMY (2019) Cardiovascular outcomes in trials of new antidiabetic drug classes: A network meta-analysis. Cardiovasc Diabetol 18, 112.

[11] Religa D, Fereshtehnejad SM, Cermakova P, Edlund AK, Garcia-Ptacek S, Granqvist N, Hallback A, Kawe K, Farahmand B, Kilander L, Mattsson UB, Nagga K, Nordstrom P, Wijk H, Wimo A, Winblad B, Eriksdotter M (2015) SveDem, the Swedish Dementia Registry - a tool for improving the quality of diagnostics, treatment and care of dementia patients in clinical practice. PLoS One 10, e0116538.

[12] Eriksdotter M, Kåwe K, Mattsson UB, Nilsson A, Mayer-Standar S, Nägga K, Sjöblom A, Wijk H, Wimo A, Winblad B, Edlund AK, Timerdal E, Westling K (2019) Svenska Demensregistret Årsrapport 2018. https://www. ucr.uu.se/svedem/om-svedem/arsrapporter/svedem-arsrapp ort-2018-2/viewdocument/967.

[13] Garcia-Ptacek S, Kramberger MG (2016) Parkinson disease and dementia. J Geriatr Psychiatry Neurol 29, 261-270.

[14] Ludvigsson JF, Almqvist C, Bonamy AK, Ljung R, Michaelsson K, Neovius M, Stephansson O, Ye W (2016) Registers of the Swedish total population and their use in medical research. Eur J Epidemiol 31, 125-136.

[15] Ludvigsson JF, Andersson E, Ekbom A, Feychting M, Kim JL, Reuterwall C, Heurgren M, Olausson PO (2011) External review and validation of the Swedish national inpatient register. BMC Public Health 11, 450.

[16] World Health Organization (1993) The International Classification of Diseases 10th Revision (ICD-10).

[17] Charlson ME, Pompei P, Ales KL, MacKenzie CR (1987) A new method of classifying prognostic comorbidity in longitudinal studies: Development and validation. J Chronic Dis 40, 373-383.

[18] Quan H, Sundararajan V, Halfon P, Fong A, Burnand B, Luthi JC, Saunders LD, Beck CA, Feasby TE, Ghali WA (2005) Coding algorithms for defining comorbidities in ICD-9-CM and ICD-10 administrative data. Med Care 43, 1130-1139.

[19] Ludvigsson JF, Svedberg P, Olen O, Bruze G, Neovius M (2019) The longitudinal integrated database for health insurance and labour market studies (LISA) and its use in medical research. Eur J Epidemiol 34, 423-437.

[20] Wettermark B, Hammar N, Fored CM, Leimanis A, Otterblad Olausson P, Bergman U, Persson I, Sundstrom A, Westerholm B, Rosen M (2007) The new Swedish Prescribed Drug Register-opportunities for pharmacoepidemiological research and experience from the first six months. Pharmacoepidemiol Drug Saf 16, 726-735.

[21] Secnik J, Schwertner E, Alvarsson M, Hammar N, Fastbom J, Winblad B, Garcia-Ptacek S, Religa D, Eriksdotter M (2020) Cholinesterase inhibitors in patients with diabetes mellitus and dementia: An open-cohort study of $\sim 23000$ patients from the Swedish Dementia Registry. BMJ Open Diabetes Res Care 8, e000833.

[22] Brooke HL, Talback M, Hornblad J, Johansson LA, Ludvigsson JF, Druid H, Feychting M, Ljung R (2017) The Swedish cause of death register. Eur J Epidemiol 32, 765-773.

[23] Robins JM, Hernan MA, Brumback B (2000) Marginal structural models and causal inference in epidemiology. Epidemiology 11, 550-560.

[24] Fewell Z, Hernan MA, Wolfe F, Tilling K, Choi H, Sterne JAC (2004) Controlling for time-dependent confounding using marginal structural models. Stata J 4, 402-420.

[25] Royston P, Parmar MK (2002) Flexible parametric proportional-hazards and proportional-odds models for censored survival data, with application to prognostic modelling and estimation of treatment effects. Stat Med 21, 2175-2197.

[26] R Core Team. R: A language and environment for statistical computing. R Foundation for Statistical Computing, Vienna, Austria. https://www.R-project.org/.

[27] Campbell JM, Bellman SM, Stephenson MD, Lisy K (2017) Metformin reduces all-cause mortality and diseases of ageing independent of its effect on diabetes control: A systematic review and meta-analysis. Ageing Res Rev 40, 31-44.

[28] Picone P, Nuzzo D, Caruana L, Messina E, Barera A, Vasto S, Di Carlo M (2015) Metformin increases APP expression and processing via oxidative stress, mitochondrial 
dysfunction and NF- $\kappa \mathrm{B}$ activation: Use of insulin to attenuate metformin's effect. Biochim Biophys Acta 1853, 1046-1059.

[29] Son SM, Shin HJ, Byun J, Kook SY, Moon M, Chang YJ, Mook-Jung I (2016) Metformin facilitates amyloid-beta generation by beta- and gamma-secretases via autophagy activation. J Alzheimers Dis 51, 1197-1208.

[30] Nystrom T, Bodegard J, Nathanson D, Thuresson M, Norhammar A, Eriksson JW (2017) Novel oral glucoselowering drugs are associated with lower risk of all-cause mortality, cardiovascular events and severe hypoglycaemia compared with insulin in patients with type 2 diabetes. Diabetes Obes Metab 19, 831-841.

[31] (2018) National Board of Health and Welfare / Socialstyrelsen: National Guidelines for Diabetes Care. Support for governance and management / Nationella Riktlinjer för Diabetesvård. Stöd för Styrning och Ledning. Accessible online: https://www.socialstyrelsen.se/globalassets/share point-dokument/artikelkatalog/nationella-riktlinjer/201810-25.pdf.

[32] Secnik J, Xu H, Schwertner E, Hammar N, Alvarsson M, Winblad B, Eriksdotter M, Garcia-Ptacek S, Religa D (2020) Dementia diagnosis is associated with changes in antidiabetic drug prescription: An open-cohort study of $\approx 130,000$ Swedish subjects over 14 years. J Alzheimers Dis 76, 15811594.

[33] Hemmingsen B, Christensen LL, Wetterslev J, Vaag A, Gluud C, Lund SS, Almdal T (2012) Comparison of metformin and insulin versus insulin alone for type 2 diabetes: Systematic review of randomised clinical trials with metaanalyses and trial sequential analyses. BMJ 344, e1771.

[34] Gamble JM, Simpson SH, Eurich DT, Majumdar SR, Johnson JA (2010) Insulin use and increased risk of mortality in type 2 diabetes: A cohort study. Diabetes Obes Metab 12, 47-53.

[35] Holden SE, Jenkins-Jones S, Morgan CL, Schernthaner G, Currie CJ (2015) Glucose-lowering with exogenous insulin monotherapy in type 2 diabetes: Dose association with allcause mortality, cardiovascular events and cancer. Diabetes Obes Metab 17, 350-362.

[36] Gamble JM, Chibrikov E, Twells LK, Midodzi WK, Young SW, MacDonald D, Majumdar SR (2017) Association of insulin dosage with mortality or major adverse cardiovascular events: A retrospective cohort study. Lancet Diabetes Endocrinol 5, 43-52.

[37] Albanese E, Taylor C, Siervo M, Stewart R, Prince MJ, Acosta D (2013) Dementia severity and weight loss:
A comparison across eight cohorts. The 10/66 study. Alzheimers Dement 9, 649-656.

[38] Varvaki Rados D, Catani Pinto L, Reck Remonti L, Bauermann Leitao C, Gross JL (2016) The association between sulfonylurea use and all-cause and cardiovascular mortality: A meta-analysis with trial sequential analysis of randomized clinical trials. PLoS Med 13, e1001992.

[39] Azoulay L, Suissa S (2017) Sulfonylureas and the risks of cardiovascular events and death: A methodological metaregression analysis of the observational studies. Diabetes Care 40, 706-714.

[40] Longato E, Di Camillo B, Sparacino G, Tramontan L, Avogaro A, Fadini GP (2020) Better cardiovascular outcomes of type 2 diabetic patients treated with GLP-1 receptor agonists versus DPP-4 inhibitors in clinical practice. Cardiovasc Diabetol 19, 74.

[41] Bethel MA, Patel RA, Merrill P, Lokhnygina Y, Buse JB, Mentz RJ, Pagidipati NJ, Chan JC, Gustavson SM, Iqbal N, Maggioni AP, Ohman P, Poulter NR, Ramachandran A, Zinman B, Hernandez AF, Holman RR, Group ES (2018) Cardiovascular outcomes with glucagon-like peptide-1 receptor agonists in patients with type 2 diabetes: A meta-analysis. Lancet Diabetes Endocrinol 6, 105-113.

[42] Wu JH, Foote C, Blomster J, Toyama T, Perkovic V, Sundstrom J, Neal B (2016) Effects of sodium-glucose cotransporter-2 inhibitors on cardiovascular events, death, and major safety outcomes in adults with type 2 diabetes: A systematic review and meta-analysis. Lancet Diabetes Endocrinol 4, 411-419.

[43] Longato E, Di Camillo B, Sparacino G, Gubian L, Avogaro A, Fadini GP (2020) Cardiovascular outcomes of type 2 diabetic patients treated with SGLT-2 inhibitors versus GLP1 receptor agonists in real-life. BMJ Open Diabetes Res Care 8, e001451.

[44] Suissa S (2018) Lower risk of death with SGLT2 inhibitors in observational studies: Real or bias? Diabetes Care 41, 6-10.

[45] Zinman B, Wanner C, Lachin JM, Fitchett D, Bluhmki E, Hantel S, Mattheus M, Devins T, Johansen OE, Woerle HJ, Broedl UC, Inzucchi SE, EMPA-REG OUTCOME Investigators (2015) Empagliflozin, cardiovascular outcomes, and mortality in type 2 diabetes. $N$ Engl J Med 373, 2117-2128.

[46] Qiu C, von Strauss E, Backman L, Winblad B, Fratiglioni L (2013) Twenty-year changes in dementia occurrence suggest decreasing incidence in central Stockholm, Sweden. Neurology 80, 1888-1894. 